\title{
Efficacy of psychosocial intervention in patients with mild Alzheimer's disease: the multicentre, rater blinded, randomised Danish Alzheimer Intervention Study (DAISY)
}

\author{
(c) (1) (9)
}

\begin{abstract}
F B Waldorff associate research professor ${ }^{12}$, D V Buss lawyer ${ }^{1}$, A Eckermann research assistant ${ }^{1}$, M L H Rasmussen research assistant ${ }^{1}$, N Keiding professor of biostatistics ${ }^{3}$, S Rishøj registered nurse $^{1}$, V Siersma senior statistician ${ }^{2}$, J Sørensen professor of health economy ${ }^{4}$, L V Sørensen occupational therapist ${ }^{1}$, A Vogel neuropsychologist ${ }^{1}$, G Waldemar professor of neurology ${ }^{1}$
\end{abstract}

${ }^{1}$ The Memory Disorders Research Group, Department of Neurology, Rigshospitalet, Copenhagen University Hospital, 9 Blegdamsvej, 2100 Copenhagen, Denmark; ${ }^{2}$ Research Unit and Department of General Practice, Institute of Public Health, University of Copenhagen; ${ }^{3}$ Department of Biostatistics, Institute of Public Health, University of Copenhagen; ${ }^{4}$ Centre for Applied Health Services Research and Technology Assessment (CAST), University of Southern Denmark, Denmark

\begin{abstract}
Objective To assess the efficacy at 12 months of an early psychosocial counselling and support programme for outpatients with mild Alzheimer's disease and their primary care givers.

Design Multicentre, randomised, controlled, rater blinded trial.

Setting Primary care and memory clinics in five Danish districts.

Participants 330 outpatients with mild Alzheimer's disease and their 330 primary care givers.

Interventions Participating dyads (patient and primary care giver) were randomised to control support during follow-up or to control support plus DAISY intervention (multifaceted and semi-tailored counselling, education, and support).
\end{abstract}

Main outcome measures Primary outcomes at 12 months for patients were change from baseline in mini mental state examination (MMSE) score, Cornell depression scale score, and proxy rated European quality of life visual analogue scale (EQ-VAS) score. For care givers, outcomes were change from baseline in geriatric depression scale (GDS 30 items) score and EQ-VAS score.

Results Because of multiple testing, statistical significance was set at an adjusted $P$ limit of $<0.0005$. At 12 months there were no significant differences between the two allocation groups in changes from baseline in the primary and secondary outcomes. However, although non-significant with the adjusted $\mathrm{P}$ limit, a small difference was observed for one of the primary patient outcomes (Cornell depression scale score) in patients in favour of the DAISY intervention group before and after adjusting for attrition ( $\mathrm{P}=0.0146$ and $\mathrm{P}=0.0103$ respectively).

Conclusions The multifaceted, semi-tailored intervention with counselling, education, and support for patients with mild Alzheimer's disease and their care givers did not have any significant effect beyond that with well structured follow-up support at 12 months after adjustment for multiple comparisons. The small positive effect found in the unadjusted primary outcome addressing depressive symptoms in patients may call for further research focusing on patients with Alzheimer's disease and comorbid depression.

Trial registration ISRCTN74848736.

\section{Introduction}

Alzheimer's disease is a common neurodegenerative disease characterised by progressive decline in cognitive, social, and occupational function, and often associated with affective symptoms and behavioural disturbances. ${ }^{1}$ Alzheimer's disease accounts for $60-80 \%$ of all cases of dementia, and recent figures indicate that as many as 35 million people worldwide have dementia, which is projected to increase to 65 million within the next two decades. ${ }^{2}$

Most patients with Alzheimer's disease reside in the community and require assistance and supervision from care givers. Being 
a family care giver for a patient with dementia is associated with a greater risk of developing both somatic and psychiatric health problems. ${ }^{3-5}$ Several studies have consistently shown that counselling and psychosocial interventions for care givers may have a significant positive effect in patients with moderate to severe Alzheimer's disease ${ }^{6-8}$ as well as in their care givers. ${ }^{6-18}$ However, in general the results have been inconsistent and the quality of studies not optimal, and a need for appropriately designed trials has been pointed out. ${ }^{19}$

With increased public awareness and better diagnostic methods, patients with Alzheimer's disease are now often diagnosed in the early phase of their disease. Many patients with mild dementia have some awareness of their own situation and may request more attention and specific counselling programmes directed towards their needs. Hence, there is a need to develop and evaluate support programmes which focus specifically on the needs of patients with mild dementia and their care givers and which include psychosocial support for the patients as well as for the care givers.

We hypothesised that a multifaceted and semi-tailored intervention programme offered to patients and their primary care givers during the first year after a diagnosis of Alzheimer's disease might prevent the emergence of depressive symptoms and improve the quality of life of patients and care givers, and perhaps even stabilise the patients' cognitive function for some time. Thus, our aim with the Danish Alzheimer Study (DAISY) was to investigate the efficacy of a multifaceted and semi-tailored psychosocial counselling and support programme offered to recently diagnosed patients with mild Alzheimer's disease and their primary care givers.

\section{Methods \\ Study design}

We carried out a randomised controlled trial allocating patients with mild Alzheimer's disease and their primary care giver (proxy) to routine follow-up (controls, $\mathrm{n}=163$ ) or to follow-up supplemented with a multifaceted and semi-tailored intervention $(n=167)$ across five (out of 15) county districts in Denmark. Before enrolment in the trial, both patients and proxies gave written informed consent. The rationale, study design, and baseline characteristics of the study have been reported in detail previously ${ }^{20}$ and will be presented here briefly.

\section{Eligibility criteria}

Inclusion criteria for the patients were age $\geq 50$ years, diagnosis of Alzheimer's disease within the past 12 months, mini mental state examination (MMSE) score $\geq 20$, and having a primary care giver who was willing to participate in the study. A primary care giver was defined as the informal care giver who was the main person responsible for the informal care for the patient and who had regular contact (at least weekly) with the patient. All patients met the criteria for dementia according to the Diagnostic and Statistical Manual of Mental Disorders (fourth edition, DSM-IV) ${ }^{1}$ and the criteria for probable Alzheimer's disease according to the National Institute of Neurological and Communicative Disorders and Stroke and the Alzheimer's Disease and Related Disorders Association (NINCDS-ADRDA) ${ }^{21}$ or the McKeith criteria for Lewy body dementia. ${ }^{22}$ Patients classified as having mixed Alzheimer's disease had probable Alzheimer's disease plus minor vascular changes visible on cranial computed tomography that could contribute to the symptoms.
We excluded patients with severe somatic or psychiatric comorbidity (including impaired hearing or vision) that would substantially impair their cooperation in the intervention programme, patients participating in other intervention studies, and patients living in a nursing home at baseline.

All participants were followed for 12 months with assessment of all outcomes at baseline and at six and 12 months by trained raters. The raters were not informed of the patients' allocation status and did not perform more than one assessment visit for each dyad of patient and care giver.

\section{Control support during follow-up}

At the assessments at six and 12 months, the raters were instructed to accommodate the patient's and carers' typical frustration and uncertainty associated with a recent diagnosis by providing overall information and guidance, and they could facilitate contact to relevant local support programmes in both the control group and the intervention group.

\section{Multifaceted and semi-tailored intervention (DAISY intervention)}

The DAISY intervention was conducted as a supplement to the control support. It was designed with the objective of preventing or reducing depressive symptoms, impairments of health related quality of life, and loss of social network. It was tailored individually to each of the participating dyads, and it offered the participants a number of components at their disposal. The intervention programme was conducted during the initial 8-12 months. The main components are described below; further details are given in our previous paper. ${ }^{20}$

Counselling sessions - Up to seven counselling sessions were scheduled: two sessions with the patient and care giver; two sessions with the patient alone; two sessions with the care giver alone; and an optional network session with the patient, care giver, and family network. The general approach of the counselling was based on constructivist principles ${ }^{23}$ and supported by the use of a monitoring scheme, which was established at the initial meeting and then used to focus follow-up sessions in consensus with the ideas of Ishiayma. ${ }^{24}$ The principles and methods were anchored on the dynamics that characterises the patient's and care giver's everyday life. The counselling was based on a philosophical approach in which each patient or care giver was given the possibility of expressing his or her life story and what is of personal importance and of great value. The counsellor offered the participants guidance with common decision making, advice, and activities that help the participants construct a meaningful life. Written notes were used to focus follow-up sessions with the aim of improving coping strategies and empowering the participants to focus on the positive factors and resources in their lives, according to the principles of self validation. A designated nurse undertook all counselling sessions after having had special training in the constructivist approach. Centres participating in the study decided individually whether counselling was undertaken in the patient's home or at the centre.

Courses-Two parallel lines of five courses each were targeted at patients and care givers respectively. The objective of the courses was to provide a basic knowledge about the disease and its consequences along with establishing a forum for patients' and care givers' exchange of experiences and coping strategies. The courses for patients included information on key issues of the disease and its consequences supported by printed handouts with information on specific topics. The courses for care givers included a more formalised education programme on 
Alzheimer's disease, also supported by printed handouts with information on specific topics. The two course lines were each scheduled for 12 participants per session being run by one counsellor and one invited teacher. All courses were planned to last two hours. A full intervention was defined when patients and care givers participated in three or more counselling sessions and three or more courses.

Additional intervention-During the intervention period the study coordinator contacted the participants by telephone about five to eight times at three or four weeks intervals. The calls focused on issues discussed at the individual sessions and education courses, but sometimes the conversations included other issues relevant for the individual participant. Patients and care givers were also supplied with comprehensive written information to support the information given at counselling sessions and courses and a log book in which they could write information and thoughts about their daily life.

\section{Study outcomes}

This study is to be considered as an exploratory randomised controlled trial since we could not identify similar studies. Thus, we operated with three primary outcomes for the patient and two primary outcomes for the principal care giver at 12 months. Primary outcomes for patients were change from baseline in mini mental state examination (MMSE) score, Cornell depression scale score, and proxy rated quality of life (EQ-VAS) score. For care givers, outcomes were change from baseline in geriatric depression scale (GDS 30 items) score and EQ-VAS score.

Primary outcomes for patients:

1. Mini mental state examination (MMSE) ${ }^{25}$ - This includes 11 items focusing on cognitive aspects of mental functions. The score ranges from 0 to 30 , with higher scores indicating better cognitive performance. In the DAISY study all patients had a MMSE score $\geq 20$ at baseline in order to comply with the inclusion criteria.

2. Cornell depression scale for dementia ${ }^{26}$ - Based on impressions from interviews with both patient and care giver, the interviewing clinicians rated depressive symptoms in the patients according to the scale. The scale consists of 19 items that each ranges from 0 (no problems) to 2 (severe problems). Thus, the total score ranges from 0 to 38 , with higher values indicating more depressive symptoms.

3. European quality of life visual analogue scale (EQ-VAS) proxy rated ${ }^{27}$-The care givers completed the Danish validated version of EQ-5D, rating their impression of the patient's health related quality of life. ${ }^{28}$ We used the VAS subscale, which ranges from 0 to 100 with higher values indicating better quality of life as outcome.

Primary outcomes for principal care givers:

1. Geriatric depression scale (GDS) ${ }^{29}$ - The care givers completed the Danish validated version of the GDS, with

30 items. One point is assigned to each answer and corresponds to a scoring grid. A score of 10 or 11 is the usual threshold to separate depressed from non-depressed individuals.

2. EQ-VAS ${ }^{27}$ - The care givers completed the Danish validated version of EQ-5D rating their impression of their own health related quality of life. ${ }^{28}$ We used the VAS subscale.

This study also included five secondary outcomes: EQ-VAS (patient rated), ${ }^{27}$ quality of life scale for Alzheimer's disease (QoL-AD) (both patient and proxy rated), ${ }^{30}$ the neuropsychiatric inventory questionnaire (NPI-Q) ${ }^{31}$ and the Alzheimer's Disease Cooperative Study activities of daily living scale (ADSC-ADL) ${ }^{32}$ for clinical trials in Alzheimer's disease (table $1 \Downarrow$ ).

\section{Sample size}

Based on mean scores and score variations for MMSE, EQ-VAS, Cornell depression scale, and GDS from previous studies in similar populations with Alzheimer's disease, ${ }^{133-35}$ we estimated that a group size of 165 was needed in order to detect a minimum effect size (defined as the difference at 12 months between groups for observed scores) of 1.2 (SD 2.6) for MMSE, 2.0 (4.4.) for Cornell depression scale, 1.8 (4.9) for GDS, and 6.0 (15) for EQ-VAS with a type I error of 5\% and type II error of $10 \%$, based on an individual analysis for each presented test. The calculations were based on a drop-out rate of $20 \%$ at 12 months. The minimum effect sizes were defined from outcomes in previous intervention studies. ${ }^{13} 3435$

\section{Randomisation}

The randomisation was done with Stat Direct version 2.3.7. We used a random block size algorithm to prevent imbalance between the allocation groups. Patients were stratified by treatment centre, MMSE score, and use of antidementia drugs. The allocation procedure was concealed for the DAISY project group and was conducted by an independent department in Rigshospitalet. At enrolment, a fax was sent to this department together with a participant code and information regarding stratification. Then the stratification was conducted, and the DAISY group received a fax with information regarding allocation status. The allocation code was concealed for the raters at follow-up visits and each rater could not rate a dyad more than once.

\section{Statistics}

Comparisons of patient and care giver sociodemographic characteristics and outcome measures at baseline between randomisation groups were done by Student's $t$ tests for continuous variables and $\chi^{2}$ tests for categorical variables. At the six and 12 month follow-ups, the outcomes in the two randomisation groups were summarised by mean and standard deviation (SD); direct comparison between groups was done by $t$ tests. To account for baseline score, we conducted an analysis of covariance, a multivariate regression relating outcome to randomisation and the baseline value of the outcome ${ }^{36}$ using generalised estimating equations to account for clustering within centres. For the comparison of baseline values, dyads with missing values were omitted. Difference in mortality between the randomisation groups was evaluated by a hazard ratio from a Cox regression model.

In further analyses, we compared the development in the outcomes between randomisation groups and analysed this with linear models using generalised estimating equations to account for repeated measurements; the inclusion of a categorical centre indicator variable accounts for possible clustering by treating centre. Differential dropout from the study may cause bias, as the dyads with disadvantageous outcomes tend to drop out, artificially favouring the group with highest dropout rate. To adjust for such bias, the measurements that were available at the six and 12 month follow-up were weighted by the inverse of an estimate of the probability of staying in the study. ${ }^{37}$ These probabilities were estimated from the data in a logistic regression model with the dyad's characteristics and the observed outcomes from previous visits as covariates. 
To adjust for multiple testing, the significance level was set to control for the false discovery rate at $5 \%$ by the procedure of Benjamini-Hochberg. ${ }^{38}$ All analyses were done in the intention to treat population-that is, dyads were analysed according to randomisation group regardless of compliance.

\section{Results}

\section{Characteristics of participants}

We screened 558 patients for eligibility and randomised 330 dyads into either DAISY intervention or control support only (figure $\Downarrow$ ). Demographics, clinical characteristics, and outcomes at baseline, stratified by allocation groups, are presented in table $1 \Downarrow$. The randomisation balanced demographics and primary outcomes. However, an imbalance in favour of the control group was observed in two secondary patient outcomes for quality of life-patient rated EQ-5D VAS $(\mathrm{P}=0.0061)$ and proxy rated QoL-AD ( $\mathrm{P}=0.0169)$.

The mean ages of patients and care givers were 76.2 years and 66.0 years, respectively. For patients, mean baseline mental state (MMSE) score was 24.1, Cornell depression scale 4.8, and proxy-rated quality of life (EQ-VAS) 63.5. For care givers, mean baseline geriatric depression scale score was 4.7 and EQ-VAS 80.4.

A total of 276 (84\%) dyads completed the 12 month follow-up assessment (figure $\downarrow$ ). At 12 months, a total of 32 dyads were lost to follow-up in the DAISY intervention group compared with 22 in the control group. In the intervention group 10 died during the 12 months, compared with three in the control group (hazard ratio 3.15 (95\% confidence interval 0.9 to 11.6 ), $\mathrm{P}=0.09$ ).

\section{Intervention}

Of the 163 dyads allocated to the DAISY intervention, 157 received the intervention, three dropped out because of the intervention being too demanding for care givers, one dropped out because the intervention was too demanding for the patient, one dropped out because the patient was hospitalised, and one dropped out because the patient died before the intervention started. Table $2 \Downarrow$ shows the participation rate in the individual components of the DAISY intervention. A total of 118 (72\%) in the DAISY intervention group completed the full intervention according to our definition.

\section{Efficacy}

Tables $3 \Downarrow$ and $4 \Downarrow$ present the results for primary and secondary outcomes at six and 12 months (adjusted for attrition). Because of multiple testing, differences with $\mathrm{P}<0.0005$ were determined to be statistically significant. None of the primary and secondary outcomes was significantly different in the two groups. At 12 months, change from baseline for one of the primary patient outcomes, Cornell depression scale score, indicated a small difference in favour of the intervention group $(\mathrm{P}=0.0146)$, and this difference remained after adjustment for attrition $(\mathrm{P}=0.0103)$ (table $4 \Downarrow$ ) but not significant when applying the $\mathrm{P}$ limit corrected for multiple testing.

\section{Discussion}

\section{Principal findings}

To our knowledge this is the largest randomised study conducted in patients with mild Alzheimer's disease and their primary care givers to evaluate the effect of a multifaceted and semi-tailored psychosocial support programme. The main result was that, after adjustment for multiple comparisons, the addition of the DAISY intervention programme to structured follow-up did not have any significant effect on outcome in patients or care givers.

\section{Strengths of the study}

A recent systematic Cochrane review and meta-analysis called for new randomised controlled studies with adequate randomisation, concealment of allocation, a priori sample size calculations, and adequate rater blinding for studies directed towards patients with mild dementia. ${ }^{39}{ }^{40}$ The DAISY study met all quality criteria established by the Cochrane group.

We included only patients with recently diagnosed mild dementia who had been offered a conventional diagnostic evaluation by a local specialist in dementia. By requiring appropriate diagnostic evaluation, we wanted to exclude patients with questionable dementia and non-progressive cognitive disorders. Patients with frontotemporal dementia were not eligible for our study, as they often have other needs, they might have had difficulties in cooperating to the programme, and it may have been difficult to mix patients with different disorders in the same counselling sessions.

There is a risk that important aspects of supportive interventions, such as perceptions and attitudes concerning the programme or staff members, adverse effects, or the positive aspects of sharing experiences with others, could be overlooked in quantitatively designed studies. Therefore, qualitative studies are also needed, and these may help design future quantitative studies. ${ }^{41}{ }^{42} \mathrm{~A}$ qualitative study was done in a subgroup of DAISY participants. This study concluded that early tailored counselling and support may improve patients' and care givers' opportunities to adapt to the challenges of Alzheimer's disease and to maintain wellbeing. ${ }^{42}$

The aim of the DAISY intervention was to prevent the emergence of depressive symptoms and impairment of health related quality of life in patients and in their care givers, and perhaps even stabilise the patients' functional status for some time. The programme comprised counselling, information, and support to patients and their primary care givers during the initial months after a diagnosis of Alzheimer's disease had been established. Rather than focusing on compensation for lost functional abilities, the philosophy of the counselling programme was to focus on positive resources, intact functions and retained skills, and activities that patients could still take part in. A unique feature of the programme was the twin-track design with activities and information specifically directed towards the patients and towards the care givers. Another unique feature was the semi-tailored design, with some components tailored for the needs of an individual patient or care giver and with other components common for all participants. The inclusion of the family network in one of the counselling sessions, at the discretion of the patient, was meant to ensure information was available to all, to prevent stigmatisation, to identify important resources in the network, and to enable the care giver to recruit a larger network when needed.

An additional feature of the DAISY study is the potential for follow-up of the cohort far beyond the period of the study visits by using information in the systematic and comprehensive Danish healthcare registries.

\section{Limitations of the study}

Patients and care givers were invited to the study regardless of their expected or expressed needs for intervention. Thus, inclusion into the study was not restricted to patients and care givers actively seeking help. The logistics for participation in 
the study programme was quite demanding, particularly for those in the DAISY intervention group. Adherence to the many counselling meetings and courses may be difficult for some, particularly for those with impaired somatic health status, with busy care givers, or living far away from the study centre.

By the fact that a diagnosis and a care giver were required for entering the study, our population was selected. However, based on the reported baseline characteristics and on previously reported data on self rated health and social performance, the profile of patients and care givers in our study was similar to that of patients included in typical drug trials and other clinical cohort studies in mild Alzheimer's disease. ${ }^{34}{ }^{35}{ }^{43}$ It is possible that a more positive effect could have been observed if we had limited inclusion of patients and care givers to those actively seeking help or living near the counselling site, measures which might have reduced the dropout rate. On the other hand, the patient group was selected with a relatively high representation of patients with a supportive social network, and may not adequately reflect the average population of Alzheimer's disease patients.

Although the intervention was semi-tailored to the needs of individual patients, a more individualised counselling and teaching programme might well have been more beneficial.

Because there is no established consensus on primary outcomes in studies of psychosocial interventions for patients with mild dementia, the study was to some extent explorative and will contribute to the design of future studies.

Furthermore, there was little guidance from the literature for the selection of primary outcome parameters and for a priori sample size calculations. Our selection of primary efficacy measures was based on the objectives of the DAISY intervention, on results studies of psychosocial interventions for care givers to patients with more advanced dementia, and on drug trials in mild Alzheimer's disease. We only used validated questionnaires as primary and secondary outcomes. The association between patient and proxy rated quality of life even in mild Alzheimer's disease is complex. Many studies have found a significant discrepancy between these measures, which to some degree may be explained by anosognosia. ${ }^{44}$ Because long term follow-up was planned, proxy rated quality of life was preferred as the main outcome, although patient rated data were also recorded. The range of primary outcomes in the DAISY study underscores the explorative nature of the study. It also underscores the notion that the use of statistical significance to determine on which outcomes DAISY intervention may have optimal effect may overstate the evidence, because of the many related comparisons that are performed. In our power calculation we did not adjust for multiple primary outcomes or for multiple time points, indicating that the DAISY study was perhaps underpowered, although still the largest single randomised controlled trial of psychosocial intervention undertaken in patients with mild Alzheimer's disease and their primary care givers.

For ethical reasons and in order not to leave any participants in the control group without any intervention except blinded rating, both groups received a standardised structured follow-up intervention. Therefore, the attempts to provide equal treatment of both intervention and control participants in all respects other than the DAISY intervention left all participants with a service well above the level of usual care for patients with dementia in Denmark. ${ }^{45}{ }^{46}$ Thus, comparing the follow-up intervention with the DAISY intervention may have masked the potential efficacy of the DAISY intervention.

\section{Comparisons with other studies and meaning of the study}

In contrast to the DAISY study, most previous studies have investigated the efficacy of psychosocial support aimed at care givers and not at dyads. An innovative US study demonstrated sustained benefits in reducing depressive symptoms in care givers for spouses with mild to severe Alzheimer's disease with an intervention consisting of counselling and support aimed at the care giver. ${ }^{13}$ In a recent systematic review assessing the effectiveness of interventions based on information and support for informal care givers of people with dementia in community settings, 44 randomised studies were included according to quality and relevance. ${ }^{19}$ Overall the methodological quality of the studies was poor. For instance, only four of the studies included an adequate randomisation process and concealment of allocation, and a priori sample size calculations were rare. Only a few studies were blinded. Most of the studies had a maximum follow-up period of 12 months, and many reported only the positive results. The reviewers concluded that the lack of adherence to best practice in trial based studies on effectiveness was overwhelming. In general, there was a significant but very small overall effect on depressive symptoms in the care givers, which should be interpreted with caution. The meta-analysis did not identify any significant effect in other outcome parameters. The authors concluded that there is a pressing need to ensure that supportive interventions at the development stage are accompanied by good quality randomised evaluation in which outcomes that are important for clinicians and carers are measured. Subsequently, at least one recent RCT on psychosocial intervention for family carers was unable to identify any effect on the primary outcome variable. ${ }^{3}$ We have not identified any previous RCTs on psycho-social interventions for patients with mild Alzheimer's disease.

While our method of allocation met the quality standard and balanced dyads' characteristics and most outcomes at baseline, we observed an imbalance at baseline in favour of the control group on two secondary outcomes-EQ-VAS (patient rated) and QoL-AD (proxy rated) (tables $1 \Downarrow$ and $4 \Downarrow$ ). This underlines the importance of defining the outcomes as difference from baseline rather than observed scores. Furthermore, the slightly higher mortality in the DAISY intervention group may reflect the imbalances at baseline in favour of the control group..

\section{Unanswered questions and future research}

This study focused on both patients with mild Alzheimer's disease and their care givers irrespective of whether they were actively seeking help. We propose further research on interventions aimed specifically at dyads with an expressed need for help and with focus on depressive symptoms.

\section{Conclusions}

The multifaceted semi-tailored intervention programme with counselling, education, and support for patients with mild Alzheimer's disease and their care givers did not have any significant effect above that of well structured support (control) on primary outcomes at 12 months after adjustment for multiple comparisons. The small positive difference between allocation groups for depressive symptoms in patients (although not significant when adjusting $\mathrm{P}$ values for multiple comparisons) may call for further research focusing on patients with Alzheimer's disease and comorbid depression. Furthermore, future studies of intensive psychosocial intervention programmes in mild Alzheimer's disease may benefit from focusing on 
patients and care givers who express a need for help and support, rather than on unselected patients.

We thank 128 volunteer raters and assistants from the 68 municipalities and five counties and the following project coordinators and physicians in the five participating centres for their help in patient recruitment, intervention, and data collection Ribe County: Esbjerg Hospital, Department of Psychiatry (Anna Marie Hansen, Johanne Christensen, Joergen Jensen). Ringkoebing County: Herning Hospital, Department of Psychiatry (Marianne Refslund, Birgitte Aagaard, Palle Lund) and Holstebro Hospital, Department of Psychiatry (Inge Lund Petersen, Finn Andersen). Roskilde County: Roskilde Hospital, Department of Geriatrics (Dorte Dyre, Lisbeth Petersen, Birgitte Froelund, Lise Korbo, Ellen Holm) and Department of Neurology (Kurt Luedorff). Vestsjaelland County: Korsoer Hospital, Department of Geriatrics (Mette Lassen, Lars Laugesen) and Dianalund Hospital, Department of Psychiatry (Thyge Jensen, Ole Bjoern Skausig). Copenhagen Capital area: Hvidovre Hospital, Department of Geriatrics (Lillian Moerk Joergensen), Amager Hospital, Department of Geriatrics (Suzanne Sanders), Bispebjerg Hospital, Department of Geriatrics (Claus Moe), Frederiksberg Community Health Care Centre (Ingrid Lauridsen), Frederiksberg Hospital, Department of Psychiatry (Rene Klysner), Glostrup Hospital, Department of Neurology, (Jens Feilberg), Rigshospitalet, Department of Neurology (Eva Illemann, Peter Johannsen). We also thank Professor Mary S Mittelman for fruitful discussions.

Contributors: FBW drafted the manuscript. FBW, VS, NK, MLHR, and GW outlined the statistical analysis. VS conducted the statistical analysis in consultation with NK. FBW, AE, DVB, and GW designed and conducted the DAISY study. All authors assisted in editing this manuscript. All authors read and approved the final manuscript. Funding: The DAISY study was supported by the National Board of Social Services at the Danish Ministry of Social Affairs, the Danish Ministry of Health and the Danish Health Foundation. All researchers were independent from the funders, and the funders were not involved in the collection, analysis, and interpretation of data, in the writing of the report, or in the decision to submit the article for publication.

Competing interest: All authors have completed the ICMJE uniform disclosure form at www.icmje.org/coi_disclosure.pdf (available on request from the corresponding author) and declare: GW had support from the National Board of Social Services at the Danish Ministry of Social Affairs, the Danish Ministry of Health, and the Danish Health Foundation for the submitted work; no financial relationships with any organisations that might have an interest in the submitted work in the previous three years; no other relationships or activities that could appear to have influenced the submitted work.

Ethical approval: The DAISY trial was conducted in accordance with the Helsinki Declaration. According to the Danish Act on Research Ethics, approval from the regional ethical committee was not required. However, we presented the protocol to the regional ethical committee for Copenhagen and Frederiksberg municipalities. The committee reported that no approval was needed (ID No (KF) 02-005/04). The Danish Data Protection Agency approved the research database (ID No 2003-41-3178).

Data sharing: The dataset is available from the corresponding author at fransw@sund.ku.dk.

American Psychiatric Association. Diagnostic and statistical manual of mental disorders .4th ed. American Psychiatric Association, 1994.

2 Alzheimer's Association. Alzheimer's disease facts and figures. Alzheimers Dement 2009:5:234-70.

3 Ulstein ID, Sandvik L, Wyller TB, Engedal K. A one-year randomized controlled psychosocial intervention study among family carers of dementia patients-effects on patients and carers. Dement Geriatr Cogn Disord 2007;24:469-75.

4 Schulz R, O'Brien AT, Bookwala J, Fleissner K. Psychiatric and physical morbidity effects of dementia caregiving: prevalence, correlates, and causes. Gerontologist 1995;35:771-91

5 Schulz R, Beach SR. Caregiving as a risk factor for mortality: the Caregiver Health Effects Study. JAMA 1999;282:2215-9.
6 Brodaty H, McGilchrist C, Harris L, Peters KE. Time until institutionalization and death in patients with dementia. Role of caregiver training and risk factors. Arch Neurol 1993;50:643-50.

7 Brodaty $\mathrm{H}$, Green $\mathrm{A}$, Koschera A. Meta-analysis of psychosocial interventions for caregivers of people with dementia. J Am Geriatr Soc 2003;51:657-64.

8 Mittelman MS, Ferris SH, Shulman E, Steinberg G, Levin B. A family intervention to delay nursing home placement of patients with Alzheimer disease. A randomized controlled trial. JAMA 1996;276:1725-31.

9 Sorensen S, Pinquart M, Duberstein P. How effective are interventions with caregivers? An updated meta-analysis. Gerontologist 2002;42:356-72.

10 Schulz R, O'Brien A, Czaja S, Ory M, Norris R, Martire LM, et al. Dementia caregiver intervention research: in search of clinical significance. Gerontologist 2002;42:589-602.

11 Pusey $\mathrm{H}$, Richards D. A systematic review of the effectiveness of psychosocial interventions for carers of people with dementia. Aging Ment Health 2001;5:107-19.

12 Pinquart M, Sorensen S. Helping caregivers of persons with dementia: which interventions work and how large are their effects? Int Psychogeriatr 2006;18:577-95.

13 Mittelman MS, Roth DL, Coon DW, Haley WE. Sustained benefit of supportive intervention for depressive symptoms in caregivers of patients with Alzheimer's disease. Am J Psychiatry 2004;161:850-6.

14 Mittelman MS, Brodaty H, Wallen AS, Burns A. A three-country randomized controlled trial of a psychosocial intervention for caregivers combined with pharmacological treatment for patients with Alzheimer disease: effects on caregiver depression. Am J Geriatr Psychiatry 2008;16:893-904.

15 Cooke DD, McNally L, Mulligan KT, Harrison MJ, Newman SP. Psychosocial interventions for caregivers of people with dementia: a systematic review. Aging Ment Health 2001;5:120-35.

16 Acton GJ, Kang J. Interventions to reduce the burden of caregiving for an adult with dementia: a meta-analysis. Res Nurs Health 2001;24:349-60.

17 Livingston G, Johnston K, Katona C, Paton J, Lyketsos CG. Systematic review of psychological approaches to the management of neuropsychiatric symptoms of dementia. Am J Psychiatry 2005;162:1996-2021.

18 Olazaran J, Reisberg B, Clare L, Cruz I, Pena-Casanova J, Del ST, et al. Nonpharmacological therapies in Alzheimer's disease: a systematic review of efficacy. Dement Geriatr Cogn Disord 2010;30:161-78.

19 Thompson CA, Spilsbury K, Hall J, Birks Y, Barnes C, Adamson J. Systematic review of information and support interventions for caregivers of people with dementia. BMC Geriatr 2007;7:18.

20 Waldemar G, Waldorff FB, Buss DV, Eckermann A, Keiding N, Rishoj S, et al. The Danish Alzheimer Intervention Study: rationale, study design and baseline characteristics of the cohort. Neuroepidemiology 2010;36:52-61.

21 McKhann G, Drachman D, Folstein M, Katzman R, Price D, Stadlan EM. Clinical diagnosis of Alzheimer's disease: report of the NINCDS-ADRDA work group under the auspices of Department of Health and Human Services Task Force on Alzheimer's Disease. Neurology 1984:34:939.

22 McKeith IG, Dickson DW, Lowe J, Emre M, O'Brien JT, Feldman H, et al. Diagnosis and management of dementia with Lewy bodies: third report of the DLB Consortium. Neurology 2005;65:1863-72

23 Peavy VR. Sociodynamic counselling: a constructivist perspective for the practice of counselling in the 21st century. Trafford Publishing, 1997.

24 Ishiyama FI. On self-validation. Trumpeter [online] 1993;10:2-8.

25 Folstein MF, Folstein SE, McHugh PR. "Mini-mental state." A practical method for grading the cognitive state of patients for the clinician. J Psychiatr Res 1975;12:189-98.

26 Alexopoulos GS, Abrams RC, Young RC, Shamoian CA. Cornell ccale for depression in dementia. Biol Psychiatry 1988;23:271-84.

27 EuroQol-a new facility for the measurement of health-related quality of life. The EuroQol Group. Health Policy 1990;1:199-208.

28 Rabin R, de Charro F. EQ-5D: a measure of health status from the EuroQol Group. Ann Med 2001;33:337-43

29 Yesavage JA, Brink TL, Rose TL, Lum O, Huang V, Adey M, et al. Development and validation of a geriatric depression screening scale: a preliminary report. $J$ Psychiatr Res 1982;17:37-49.

30 Logsdon RG, Gibbons LE. Quality of life in Alzheimer's disease: patients' and caregiver's reports. J Ment Health Aging 1999:5:21-32.

31 Cummings JL, Mega M, Gray K, Rosenberg-Thompson S, Carusi DA, Gornbein J. The Neuropsychiatric Inventory: comprehensive assessment of psychopathology in dementia. Neurology 1994;44:2308-14.

32 Galasko D, Bennett D, Sano M, Ernesto C, Thomas R, Grundman M, et al. An inventory to assess activities of daily living for clinical trials in Alzheimer's disease. The Alzheimer's Disease Cooperative Study. Alzheimer Dis Assoc Disord 1997;11(suppl 2):S33-9.

33 Jonsson L, Andreasen N, Kilander L, Soininen H, Waldemar G, Nygaard H, et al. Patientand proxy-reported utility in Alzheimer disease using the EuroQoL. Alzheimer Dis Assoc Disord 2006;20:49-55

34 Seltzer B, Zolnouni P, Nunez M, Goldman R, Kumar D, leni J, et al. Efficacy of donepezil in early-stage Alzheimer disease: a randomized placebo-controlled trial. Arch Neurol 2004:61:1852-6.

35 Winblad B, Engedal K, Soininen H, Verhey F, Waldemar G, Wimo A, et al. A 1-year, randomized, placebo-controlled study of donepezil in patients with mild to moderate $A D$. Neurology 2001;57:489-95.

36 Vickers AJ, Altman DG. Statistics notes: analysing controlled trials with baseline and follow up measurements. BMJ 2001;323:1123-4.

37 Dufouil C, Brayne C, Clayton D. Analysis of longitudinal studies with death and drop-out: a case study. Stat Med 2004:23:2215-26.

38 Benjamini $Y$, Hochberg $Y$. Controlling the false iscovery rate: a practical and powerful approach to multiple testing. J Royal Stat Soc B (Methodological) 1995;57:289-300.

39 Thompson CA, Spilsbury K, Barnes C. Information and support interventions for carers of people with dementia (Protocol). Cochrane Database of Systematic Reviews, 2003.

40 Nelis S, Quinn C, Clare L. Information and support interventions for informal caregivers of people with dementia (Protocol). Cochrane Database of Systematic Reviews, 2007.

41 Lavoie JP, Ducharme F, Levesque L, Hebert R, Vezina J, Gendron C, et al. Understanding the outcomes of a psycho-educational group intervention for caregivers of persons with dementia living at home: a process evaluation. Aging Ment Health 2005;9:25-34.

42 Sorensen LV, Waldorff FB, Waldemar G. Early counselling and support for patients with mild Alzheimer's disease and their caregivers: a qualitative study on outcome. Aging Ment Health 2008;12:444-50. 


\section{What is already known on this topic}

Counselling and psychosocial interventions for care givers may have a significant positive effect in patients with moderate to severe Alzheimer's disease and their care givers

Few studies have intervened for both the patients with Alzheimer's disease and their care givers, and none has involved patients with very mild Alzheimer's disease.

\section{What this study adds}

An intensive, multifaceted, semi tailored intervention programme with counselling, education, and support to patients with mild Alzheimer's disease and their care givers did not improve outcomes for either compared with well structured follow-up support.

43 Reynish E, Cortes F, Andrieu S, Cantet C, Olde RM, Melis R, et al. The ICTUS Study: a prospective longitudinal observational study of 1,380 AD patients in Europe. Study design and baseline characteristics of the cohort. Neuroepidemiology 2007;29:29-38.

44 Vogel A, Mortensen EL, Hasselbalch SG, Andersen BB, Waldemar G. Patient versus informant reported quality of life in the earliest phases of Alzheimer's disease. Int $J$ Geriatr Psychiatry 2006;21:1132-8

45 Waldemar G, Phung KT, Burns A, Georges J, Hansen FR, lliffe S, et al. Access to diagnostic evaluation and treatment for dementia in Europe. Int $J$ Geriatr Psychiatry 2007;22:47-54.

46 Phung TK, Andersen BB, Kessing LV, Mortensen PB, Waldemar G. Diagnostic evaluation of dementia in the secondary health care sector. Dement Geriatr Cogn Disord 2009;27:534-42.
Accepted: 27 June 2012

\section{Cite this as: BMJ 2012;345:e4693}

This is an open-access article distributed under the terms of the Creative Commons Attribution Non-commercial License, which permits use, distribution, and reproduction in any medium, provided the original work is properly cited, the use is non commercial and is otherwise in compliance with the license. See: http://creativecommons.org/licenses/by$\mathrm{nc} / 2.0 /$ and http://creativecommons.org/licenses/by-nc/2.0/legalcode. 


\section{Tables}

Table 1| Baseline characteristics of patients with Alzheimer's disease and their care givers who participated in the Danish Alzheimer Intervention Study (DAISY). Values are numbers (percentages) of participants unless stated otherwise

\begin{tabular}{|c|c|c|}
\hline & Intervention $(n=163)$ & Control $(n=167)$ \\
\hline \multicolumn{3}{|l|}{ Patient characteristics } \\
\hline \multicolumn{3}{|l|}{ Sex $(n=163)$ : } \\
\hline Male & $76(47)$ & $75(45)$ \\
\hline Female & $87(53)$ & $92(55)$ \\
\hline Mean (SD) age (years) & $76.5(7.7)$ & $75.9(6.6)$ \\
\hline \multicolumn{3}{|l|}{ Household status: } \\
\hline Living alone & $54(33)$ & $48(29)$ \\
\hline Living with others & $109(67)$ & $119(71)$ \\
\hline \multicolumn{3}{|l|}{ Home: } \\
\hline Rented & $66(40.5)$ & $56(33.5)$ \\
\hline Owned & $97(59.5)$ & $111(66.5)$ \\
\hline \multicolumn{3}{|l|}{ Education: } \\
\hline None & $60(36.8)$ & $57(34.1)$ \\
\hline$<3$ years & 39 (23.9) & $49(29.3)$ \\
\hline$\geq 3$ years & $64(39.3)$ & $61(36.5)$ \\
\hline \multicolumn{3}{|l|}{ Charlson comorbidity index: } \\
\hline No comorbidity & $64(39.3)$ & $73(43.7)$ \\
\hline 1 comorbidity & $75(46.0)$ & $65(38.9)$ \\
\hline$\geq 2$ comorbidities & $24(14.7)$ & $29(17.4)$ \\
\hline \multicolumn{3}{|l|}{ Diagnosis: } \\
\hline Pure Alzheimer's disease & $112(68.7)$ & $127(76.1)$ \\
\hline Mixed Alzheimer's disease and vascular dementia & $44(27.0)$ & $38(22.8)$ \\
\hline Lewy body dementia & $7(4.3)$ & $2(1.2)$ \\
\hline \multicolumn{3}{|l|}{ Caregiver characteristics } \\
\hline \multicolumn{3}{|l|}{ Sex: } \\
\hline Male & $54(33.1)$ & $56(33.5)$ \\
\hline Female & $109(66.9)$ & $111(66.5)$ \\
\hline Mean (SD) age (years) & $65.5(12.7)$ & $66.5(12.7)$ \\
\hline \multicolumn{3}{|l|}{ Relation: } \\
\hline Spouse & $104(63.8)$ & $111(66.5)$ \\
\hline Child or child in law & $45(27.6)$ & $41(24.5)$ \\
\hline Other & $14(8.6)$ & $15(9.0)$ \\
\hline \multicolumn{3}{|l|}{ Lives with patient: } \\
\hline Yes & $101 / 162(62.4)$ & $112 / 166(67.5)$ \\
\hline No & $61 / 162(37.6)$ & $54 / 166(32.5)$ \\
\hline \multicolumn{3}{|l|}{ Home: } \\
\hline Rented & $45(27.6)$ & $45(26.9)$ \\
\hline Owned & $118(72.4)$ & $122(73.1)$ \\
\hline \multicolumn{3}{|l|}{ Education: } \\
\hline None & $41(25.2)$ & 37/166 (22.3) \\
\hline$<3$ years & $46(28.2)$ & 63/166 (37.9) \\
\hline$\geq 3$ years & $76(46.6)$ & 66/166 (39.8) \\
\hline \multicolumn{3}{|l|}{ Outcome measures } \\
\hline \multicolumn{3}{|l|}{ Primary patient outcomes: } \\
\hline Mean (SD) MMSE & $24.0(2.5)$ & $24.1(2.7)$ \\
\hline
\end{tabular}


Table 1 (continued)

\begin{tabular}{|c|c|c|}
\hline & Intervention $(n=163)$ & Control $(n=167)$ \\
\hline Mean (SD) Cornell depression scale & $5.17(4.8)$ & $4.41(4.0)$ \\
\hline \multirow[t]{2}{*}{ Mean (SD) EQ-VAS (proxy rated) } & $62.1(18.4)$ & $64.7(20.4)$ \\
\hline & $(n=162)$ & \\
\hline \multicolumn{3}{|l|}{ Primary caregiver outcomes: } \\
\hline \multirow[t]{2}{*}{ Mean (SD) EQ-VAS } & $79.3(16.3)$ & $81.4(16.3)$ \\
\hline & $(n=162)$ & \\
\hline \multirow[t]{2}{*}{ Mean (SD) GDS } & $4.74(5.16)$ & $4.71(5.02)$ \\
\hline & $(n=162)$ & \\
\hline \multicolumn{3}{|l|}{ Secondary patient outcomes: } \\
\hline \multirow[t]{2}{*}{ Mean (SD) EQ-VAS (patient rated) } & $73.6(17.1)$ & $78.8(16.5)$ \\
\hline & $(n=161)$ & \\
\hline Mean (SD) QoL-AD (patient rated) & $38.8(6.0)$ & $39.5(5.7)$ \\
\hline Mean (SD) QoL-AD (proxy rated) & $33.0(6.1)$ & $34.7(6.6)$ \\
\hline Mean (SD) NPI-Q & $3.90(3.61)$ & $3.90(3.65)$ \\
\hline Mean (SD) ADSC-ADL & $61.2(11.4)$ & $61.8(11.4)$ \\
\hline
\end{tabular}

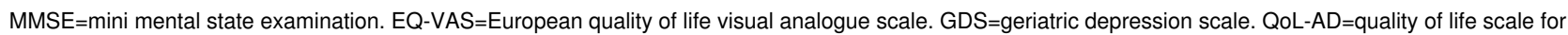
Alzheimer's disease. NPI-Q=neuropsychiatric inventory questionnaire. ADSC-ADL=Alzheimer's Disease Cooperative Study activities of daily living scale. 
Table 2| Rates of participation in the components of the DAISY (Danish Alzheimer Intervention Study) intervention among the patients with Alzheimer's disease and their care givers who were allocated to the intervention. Values are fractions $(95 \% \mathrm{Cl})$ of potential participants

\begin{tabular}{|c|c|c|}
\hline Component & Patient $(n=157)$ & Care giver $(n=157)$ \\
\hline \multicolumn{3}{|l|}{ Constructivist counselling: } \\
\hline Initial meeting & 1.00 & $0.99(0.98$ to 1.00$)$ \\
\hline 1st follow-up meeting & 0.84 (0.78 to 0.90$)$ & 0.85 (0.79 to 0.92$)$ \\
\hline 2nd follow-up meeting & $0.78(0.72$ to 0.85$)$ & $0.78(0.72$ to 0.85$)$ \\
\hline Network meeting ${ }^{\star}$ & 0.32 (0.25 to 0.39$)$ & $0.32(0.25$ to 0.40$)$ \\
\hline Final meeting & 0.83 (0.78 to 0.89$)$ & $0.82(0.76$ to 0.87$)$ \\
\hline Telephone counselling $†$ & $0.36(0.28$ to 0.43$)$ & $0.80(0.73$ to 0.86$)$ \\
\hline \multicolumn{3}{|l|}{ Courses: } \\
\hline 1st session & $0.84(0.78$ to 0.90$)$ & 0.83 (0.77 to 0.89$)$ \\
\hline 2nd session & 0.83 (0.77 to 0.89$)$ & $0.82(0.76$ to 0.88$)$ \\
\hline 3rd session & $0.76(0.70$ to 0.83$)$ & 0.77 (0.70 to 0.84$)$ \\
\hline 4th session & $0.76(0.70$ to 0.83$)$ & 0.75 (0.68 to 0.82$)$ \\
\hline 5th session & $0.76(0.70$ to 0.83$)$ & $0.74(0.66$ to 0.80$)$ \\
\hline \multicolumn{3}{|l|}{ Overall participation $\ddagger$ : } \\
\hline Participated in $\geq 3$ counsellings & 0.88 (0.83 to 0.93$)$ & 0.91 (0.87 to 0.96$)$ \\
\hline Participated in $\geq 3$ courses & 0.81 (0.75 to 0.87$)$ & 0.80 (0.74 to 0.87$)$ \\
\hline
\end{tabular}

Participation in individual meetings and sessions was determined by individual needs and preferences, which were assessed by the counsellor and participant in collaboration. Target rates were thus not necessarily 1.00 , and for that reason the conventional terminology of compliance is avoided.

*A network comprised one to four people but is considered here as one unit. Except for the network meetings, networks were not invited to attend counselling or courses; some participated in selected sessions, however.

†The patient or caregiver, or both, could register for calls.

‡Participation in three sessions of constructivist counselling (of which at least two were face to face, not by telephone) or courses was considered a high degree of concordance, given the flexible nature of the intervention. 
Table 3| Effect of the DAISY (Danish Alzheimer Intervention Study) intervention compared with control support among patients with

Alzheimer's disease and their care givers on the primary and secondary outcomes and the difference of these outcomes from baseline. Missing values are omitted from these intention to treat analyses. Values are means (standard deviations) unless stated otherwise

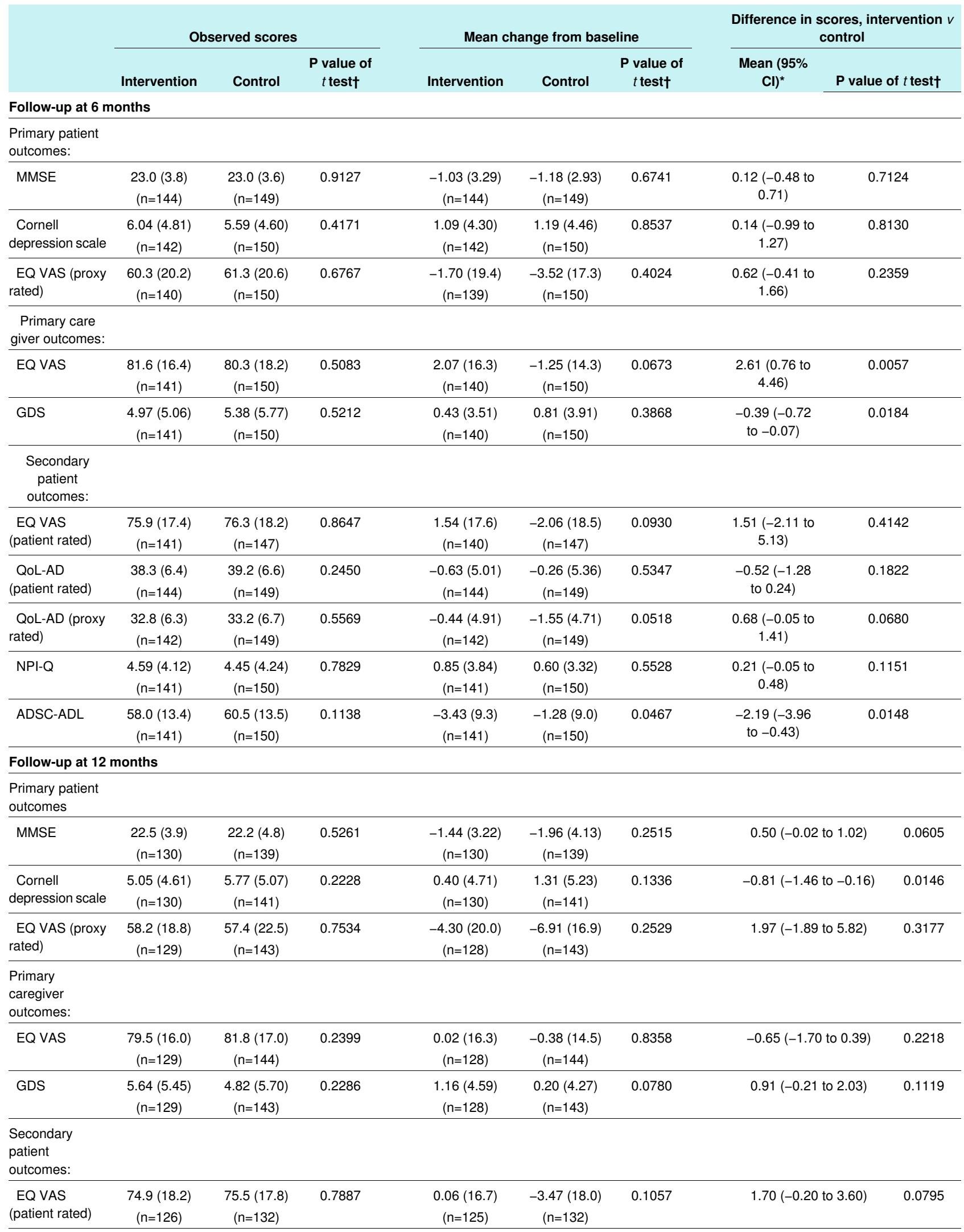


Table 3 (continued)

\begin{tabular}{|c|c|c|c|c|c|c|c|c|}
\hline \multirow[b]{3}{*}{$\begin{array}{l}\text { QoL-AD } \\
\text { (patient rated) }\end{array}$} & \multicolumn{3}{|c|}{ Observed scores } & \multicolumn{3}{|c|}{ Mean change from baseline } & \multicolumn{2}{|c|}{$\begin{array}{c}\text { Difference in scores, intervention } v \\
\text { control }\end{array}$} \\
\hline & Intervention & Control & $\begin{array}{c}\mathbf{P} \text { value of } \\
t \text { test } †\end{array}$ & Intervention & Control & $\begin{array}{l}\mathbf{P} \text { value of } \\
t \text { test } \dagger\end{array}$ & $\begin{array}{l}\text { Mean }(95 \% \\
\mathrm{Cl})^{*}\end{array}$ & $t$ test $†$ \\
\hline & $\begin{array}{c}38.2(6.6) \\
(n=129)\end{array}$ & $\begin{array}{c}38.2(6.8) \\
(n=140)\end{array}$ & 0.7184 & $\begin{array}{c}-0.91(4.61) \\
(n=129)\end{array}$ & $\begin{array}{c}-0.89(5.64) \\
(n=140)\end{array}$ & 0.9722 & $-0.08(-1.17$ to 1.01$)$ & 0.8842 \\
\hline $\begin{array}{l}\text { QoL-AD (proxy } \\
\text { rated) }\end{array}$ & $\begin{array}{c}32.6(6.2) \\
(n=130)\end{array}$ & $\begin{array}{c}32.2(6.7) \\
(n=144)\end{array}$ & 0.6128 & $\begin{array}{c}-0.70(4.64) \\
(n=130)\end{array}$ & $\begin{array}{c}-2.44(5.24) \\
(n=144)\end{array}$ & 0.0040 & $1.33(-0.019$ to 2.69$)$ & 0.0534 \\
\hline NPI-Q & $\begin{array}{c}4.79(3.82) \\
(n=129)\end{array}$ & $\begin{array}{c}4.24(4.36) \\
\quad(n=143)\end{array}$ & 0.2669 & $\begin{array}{c}1.02(3.84) \\
(n=129)\end{array}$ & $\begin{array}{c}0.33(3.91) \\
(n=143)\end{array}$ & 0.1424 & $0.63(-0.28$ to 1.55$)$ & 0.1733 \\
\hline ADSC-ADL & $\begin{array}{c}55.3(15.1) \\
(n=130)\end{array}$ & $\begin{array}{c}56.6(17.8) \\
(n=143)\end{array}$ & 0.5341 & $\begin{array}{c}-6.21(10.3) \\
(n=130)\end{array}$ & $\begin{array}{c}-5.64(12.6) \\
(n=143)\end{array}$ & 0.6851 & $-0.52(-3.26$ to 2.22$)$ & 0.7097 \\
\hline
\end{tabular}

$M M S E=m i n i$ mental state examination. $E Q-V A S=E u r o p e a n$ quality of life visual analogue scale. GDS=geriatric depression scale. $Q$ oL-AD=quality of life scale for Alzheimer's disease. NPI-Q=neuropsychiatric inventory questionnaire. ADSC-ADL=Alzheimer's Disease Cooperative Study activities of daily living scale. *The mean difference in outcome attributable to the randomisation is assessed in an analysis of covariance where the primary comparison between randomisation groups is adjusted for the baseline value of the corresponding outcome (and thereby is the same as the mean difference in change from baseline); the confidence intervals $(95 \% \mathrm{Cl})$ and $\mathrm{P}$ values corresponding to these differences are calculated using generalised estimating equations to account for correlation within treating centre.

†To control the false discovery rate at $5 \%$, a $\mathrm{P}$ value of 0.0005 is considered significant. 
Table 4| Longitudinal effect of the DAISY (Danish Alzheimer Intervention Study) intervention compared with control support among patients with Alzheimer's disease and their care givers on the primary and secondary outcomes and the difference of these outcomes from baseline (intention to treat analyses). Values are means $(95 \% \mathrm{Cl})$ unless stated otherwise*

\begin{tabular}{|c|c|c|c|c|c|c|}
\hline & \multicolumn{3}{|c|}{ Observed scores } & \multicolumn{3}{|c|}{ Mean change from baseline } \\
\hline & Intervention & Control & $\begin{array}{c}\text { P value of } t \\
\text { test† }\end{array}$ & Intervention & Control & $\begin{array}{c}\text { P value of } t \\
\text { test } \dagger\end{array}$ \\
\hline \multicolumn{7}{|l|}{ Follow-up at 6 months } \\
\hline \multicolumn{7}{|l|}{$\begin{array}{l}\text { Primary patient } \\
\text { outcomes: }\end{array}$} \\
\hline MMSE & 22.9 (22.2 to 23.5$)$ & 23.0 (22.4 to 23.6$)$ & 0.7545 & $-1.17(-1.76$ to -0.59$)$ & $-1.08(-1.58$ to -0.58$)$ & 0.8055 \\
\hline $\begin{array}{l}\text { Cornell depression } \\
\text { scale }\end{array}$ & 6.03 (5.23 to 6.82$)$ & 5.64 (4.86 to 6.71$)$ & 0.5176 & 0.85 (0.11 to 1.60$)$ & $1.23(0.50$ to 1.96$)$ & 0.4602 \\
\hline EQ VAS (proxy rated) & 59.8 (56.4 to 63.1$)$ & 61.1 (57.8 to 64.5$)$ & 0.5951 & $-2.37(-5.56$ to 0.82$)$ & $-3.56(-6.45$ to -0.68$)$ & 0.5563 \\
\hline \multicolumn{7}{|l|}{$\begin{array}{l}\text { Primary care giver } \\
\text { outcomes: }\end{array}$} \\
\hline EQ VAS & 81.4 (78.7 to 84.2 ) & 80.4 (77.5 to 83.3$)$ & 0.5765 & $2.18(-0.54$ to 4.90$)$ & $-1.00(-3.30$ to 1.30$)$ & 0.0758 \\
\hline GDS & 5.18 (4.68 to 6.12$)$ & 5.55 (4.56 to 6.55$)$ & 0.6187 & $0.44(-0.29$ to 1.16$)$ & 0.85 (0.11 to 1.58$)$ & 0.4617 \\
\hline \multicolumn{7}{|l|}{$\begin{array}{l}\text { Secondary patient } \\
\text { outcomes: }\end{array}$} \\
\hline EQ VAS (patient rated) & 75.8 (73.0 to 78.7$)$ & 76.2 (73.4 to 79.1$)$ & 0.8394 & $2.21(-0.71$ to 5.13$)$ & $-2.54(-5.50$ to 0.43$)$ & 0.0268 \\
\hline QoL-AD (patient rated) & 38.3 (37.2 to 39.3 ) & 39.1 (38.0 to 40.1 ) & 0.2854 & $-0.52(-0.37$ to 0.34$)$ & $-0.43(-1.34$ to 0.49$)$ & 0.8875 \\
\hline QoL-AD (proxy rated) & 32.6 (31.6 to 33.7 ) & 33.0 (32.0 to 34.1$)$ & 0.6138 & $-0.38(-1.24$ to 0.48$)$ & $-1.70(-2.51$ to -0.88$)$ & 0.0312 \\
\hline $\mathrm{NPI}-\mathrm{Q}$ & 4.68 (3.98 to 5.39$)$ & 4.63 (3.91 to 5.34 ) & 0.8945 & 0.78 (0.10 to 1.47$)$ & 0.72 (0.15 to 1.29$)$ & 0.8779 \\
\hline ADSC-ADL & 58.0 (55.7 to 60.2 ) & 60.4 (58.1 to 62.7$)$ & 0.1128 & $-3.27(-4.99$ to -1.55$)$ & $-1.34(-2.98$ to 0.30$)$ & 0.0964 \\
\hline \multicolumn{7}{|l|}{ Follow-up at 12 months } \\
\hline \multicolumn{7}{|l|}{$\begin{array}{l}\text { Primary patient } \\
\text { outcomes: }\end{array}$} \\
\hline MMSE & 22.5 (21.8 to 23.2$)$ & 22.3 (21.5 to 23.1$)$ & 0.7294 & $-1.55(-2.19$ to -0.91$)$ & $-1.80(-2.56$ to -1.04$)$ & 0.6502 \\
\hline $\begin{array}{l}\text { Cornell depression } \\
\text { scale }\end{array}$ & 4.97 (4.20 to 5.74$)$ & 5.79 (4.86 to 6.71$)$ & 0.1611 & $-0.20(-1.04$ to 0.64$)$ & 1.38 (0.49 to 2.27$)$ & 0.0103 \\
\hline EQ VAS (proxy rated) & 58.3 (54.8 to 61.7$)$ & 57.9 (54.0 to 61.8$)$ & 0.8798 & $-3.88(-7.38$ to -0.37$)$ & $\begin{array}{c}-6.83(-10.10 \text { to } \\
-3.56)\end{array}$ & 0.2308 \\
\hline
\end{tabular}

\section{Primary care giver}

outcomes:

\begin{tabular}{lllllll}
\hline EQ VAS & $79.0(76.0$ to 81.9$)$ & $81.6(78.8$ to 84.5$)$ & 0.2034 & $-0.31(-3.41$ to 2.79$)$ & $0.20(-2.31$ to 2.71$)$ & 0.7799 \\
\hline GDS & $5.70(4.68$ to 6.72$)$ & $4.97(3.97$ to 5.97$)$ & 0.3064 & $0.96(0.05$ to 1.86$)$ & $0.26(-0.51$ to 1.03$)$ & 0.2500
\end{tabular}

Secondary patient

outcomes:

\begin{tabular}{|c|c|c|c|c|c|c|}
\hline EQ VAS (patient rated) & 74.4 (71.1 to 77.6$)$ & 74.6 (70.5 to 78.7 ) & 0.9254 & $0.73(-2.41$ to 3.88$)$ & $-4.20(-8.29$ to -0.11$)$ & 0.0667 \\
\hline QoL-AD (patient rated) & 38.0 (36.8 to 39.2 ) & 38.5 (37.3 to 39.6$)$ & 0.5812 & $-0.82(-1.77$ to 0.12$)$ & $-1.04(-2.04$ to -0.04$)$ & 0.7213 \\
\hline QoL-AD (proxy rated) & 32.6 (31.4 to 33.7$)$ & 32.1 (31.0 to 33.2) & 0.5732 & $-0.47(-1.35$ to 0.41$)$ & $-2.61(-3.58$ to -1.64$)$ & 0.0013 \\
\hline NPI-Q & 4.75 (4.09 to 5.41$)$ & 4.34 (3.56 to 5.11$)$ & 0.4273 & 0.85 (0.16 to 1.53$)$ & $0.43(-0.26$ to 1.13$)$ & 0.4045 \\
\hline ADSC-ADL & 54.8 (52.1 to 57.6$)$ & 57.1 (54.2 to 60.0$)$ & 0.2549 & $-6.39(-8.51$ to -4.27$)$ & $-4.63(-6.92$ to -2.35$)$ & 0.2689 \\
\hline
\end{tabular}

$M M S E=$ mini mental state examination. $E Q-V A S=E u r o p e a n$ quality of life visual analogue scale. GDS=geriatric depression scale. $Q$ oL-AD=quality of life scale for Alzheimer's disease. NPI-Q=neuropsychiatric inventory questionnaire. ADSC-ADL=Alzheimer's Disease Cooperative Study activities of daily living scale.

*Means are estimated from a longitudinal model where selective dropout is accounted for by inverse proportional weighting; the inclusion of a categorical indicator variable for treating centre accounts for possible clustering within centre; confidence intervals and $\mathrm{P}$ values are calculated with generalised estimating equations. †To control the false discovery rate at $5 \%$, a $P$ value of 0.0005 is considered significant. 


\section{Figure}

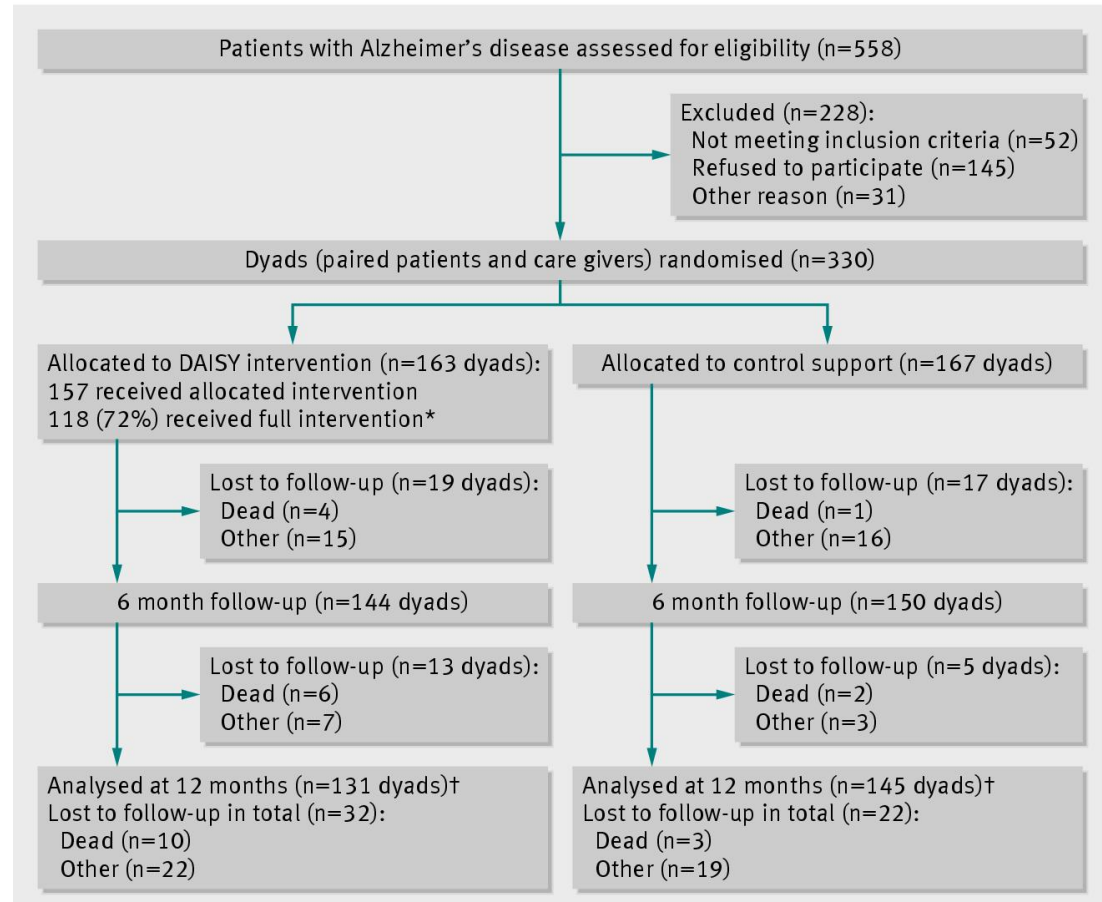

*Full compliance defined as participation from both care giver and patient in $\geq 3$ courses and $\geq 3$ counselling sessions each tAnalysis that accounted for drop-outs incorporated information from all participating dyads

Flow of participants through Danish Alzheimer Intervention Study (DAISY) 